\title{
Temporal variations in near surface soil moisture at two contrasting sites in the Wye catchment and their control on storm streamflow generation
}

\author{
G. Roberts, ${ }^{1}$ and S. B. Crane ${ }^{2}$ \\ 1 Institute of Hydrology, Wallingford OX10 8BB, UK \\ 2 Institute of Hydrology (Plynlimon), Staylittle, Llanbrynmair, Powys, SY19 7DB, UK.
}

\begin{abstract}
Near surface soil moisture measurements were recorded at hourly intervals at two contrasting sites within the Cyff sub-catchment using a prototype capacitance probe system. In a mire area within a valley bottom, over the twelve month recording period, very little change in moisture content occurred. At the other site, a well drained area on a steeply sloping hillside, major variations occurred with significant soil moisture deficits being generated during a particularly dry summer.

Soil moisture on the slope responded rapidly to rainfall inputs during wet periods, with little response during particularly dry periods. A number of rainfall events was analysed to determine whether changes in soil moisture could be used to characterise storm hydrographs for the Cyff and the Gwy, two sub-catchments being composed of differing percentages of mire area and steep slopes. It was found that percentage runoff for the Cyff was correlated with antecedent soil moisture on the slope, though the agreements for peak flow and lag time were poorer. For the Gwy, poor agreements were obtained for all three hydrograph characteristics. A simple formulation, based on storm rainfall and antecedent soil moisture deficits in the slope and mire areas, gave good agreement with storm streamflow volumes.
\end{abstract}

\section{Introduction}

Soil moisture, a key variable in the hydrological process, governs bare soil evaporation, crop transpiration, the partioning of rainfall into storm runoff and the replenishment of soil moisture stores, and groundwater recharge. Soil moisture status influences not only the amount of streamflow generated, but also its timing and the magnitude of flood peaks. Therefore, a knowledge of the spatial and temporal variation of soil moisture is useful for successful deterministic hydrological modelling.

Soil moisture status at a given site is determined by a number of factors. In addition to antecedent rainfall, these will also include the local topography, soil type, underlying geology, and vegetation. In the past, soil moisture measurements have been made either by the destructive sampling of soil cores, or by non-destructive methods such as a neutron probe (Bell and McCulloch, 1966), or by using a portable capacitance probe (Dean et al., 1987). Values from individual sites would then be combined by some pre-determined criteria to provide the variation in soil moisture over the area of interest for hydrological modelling purposes (Hasnip, 1993).

Whilst soil moisture values taken at infrequent intervals are useful for water balance purposes (Hudson, 1988), they have limited value for studying storm hydrograph generation. For this, what is required is a network of sensors providing soil moisture at frequent intervals particularly at shallow depths where soil moisture changes are likely to be greatest. Such instrumentation is expensive to install and maintain, with the number of required sites increasing as the size of the area and its heterogeneity increases. As an alternative, a small number of fixed recording stations, located at contrasting sites, could be used, provided that some means exists to extrapolate the results obtained over the area of interest. This study attempts to do this, and to assess the usefulness of the results obtained from the capacitance probes in characterizing storm hydrographs.

\section{Study area}

Two sites were selected to represent contrasting soil moisture conditions, following an analysis of soil moisture data from the network of neutron probe access tubes (Hudson, 1988) operational between 1968 and 1974. The analysis suggested that the various access tube sites could be split into 'wet' and 'dry' areas according to their position in the 
catchment and the local slope. This also determines the soil type and vegetation (Newson, 1976). 'Wet' sites were found to be mainly confined to the flat interfluve areas dominated by heathland overlying peat, and the valley bottoms composed of mire areas overlying alluvium and peat. 'Dry' sites occupy the well drained steeply sloping valley sides overlying acid brown earths and peaty podzols. The vegetation on many of these areas has been improved mainly by the addition of lime to provide increased grazing for sheep.

Two sites (no. 33 and 35) on the original Cyff neutron probe 'line' were chosen for this study. Site 35 is located in a mire area, some $300 \mathrm{~m}$ from the stream, overlying a peaty gley of the Ynys series on a local slope of approximately $3^{\circ}$. Site 33 is located some $180 \mathrm{~m}$ upslope on a well drained grassland site (local slope approximately $11^{\circ}$ ), overlying an acid brown earth of the Manod series. The initial installations of the neutron probe access tubes showed that site 33 is composed of brown earth down to $90 \mathrm{~cm}$, whilst site 35 is composed of peat down to $85 \mathrm{~cm}$ overlying clay to $190 \mathrm{~cm}$. Both stations were installed during September 1994; the mire station was operational for 12 months whilst the slope station was operational for two years.

At both sites four prototype capacitance probes (Robinson and Dean, 1993), were installed permanently at depths of $5,10,15$ and $50 \mathrm{~cm}$ below ground level. The probes at 5,10 and $15 \mathrm{~cm}$ depth were installed horizontally through the sides of individual pits which were later infilled, whilst the probe at $50 \mathrm{~cm}$ depth was installed at an angle of $45^{\circ}$ through a tube inserted into an augered hole. Both sites were also equipped with a rain gauge, which was installed within a pit so that its rim was at ground level and at the same angle as the local slope.

Each set of capacitance probes and rain gauge were connected to a control logger, and the variables recorded at hourly intervals. The capacitance probes measure water content as a frequency; this was converted to moisture volume fraction following a calibration using the gravimetric moisture volume fractions of soil cores.

\section{Method}

To determine the representivity of the two sites various methods were used; these included the classification of remotely sensed images recorded by the Landsat satellite and an analysis of a topographic index based on drainage area and local gradient (Quinn et al., 1989). Neither the topographic index or other indices based on combinations of reflectances in various Landsat bands gave a good correspondence with 'ground truths', given by long-term mean soil moisture values from the neutron probe network. Instead, it was decided to use the local slope to differentiate between wet and dry areas. This followed the collection of soil moisture measurements using a portable capacitance probe (Dean et al., 1987) along the Cyff neu- tron probe 'line' on a number of occasions. These measurements showed a distinct change in soil moisture at the break of slope, with a local slope of approximately $10^{\circ}$ being the transition point. This broadly agrees with the differentiation between soil types as given in Knapp, 1970.

Several rainfall events were analysed to study short term changes in soil moisture and to determine the effects of initial conditions on streamflow hydrograph response. Flow data from the Cyff and Gwy sub-catchments were used for this purpose. These sub-catchments are similar in size, but are different in the percentage and distribution of flat and steeply sloping $\left(>10^{\circ}\right)$ areas. These percentages, taken from Newson (1976), are as follows:

$\begin{array}{lll} & C Y F F & G W Y \\ \text { SLOPE }<10^{\circ} & 47.5 \% & 34.6 \% \\ \text { SLOPE }>10^{\circ} & 52.5 \% & 65.4 \%\end{array}$

For the Cyff, all but about $5 \%$ of the flat areas occur in the valley bottoms. For the Gwy, the flat areas are distributed equally between interfluve areas and valley bottoms. In all subsequent analysis, it has been assumed that the data from the mire site represent areas with slopes $<10^{\circ}$.

Criteria employed when choosing rainfall events required:

(i) The existence of data from both sets of capacitance probes.

(ii) Contrasting soil moisture conditions prior to the rainfall events.

(iii) Isolated rainfall events, so that their effects on the soil moisture and the streamflow hydrographs could be analysed independently from other rainfall inputs (NERC, 1975).

Individual regressions were performed between antecedent soil moisture, as given by the capacitance probes and percentage runoff, peak flow, and time to peak. Percentage runoff and time to peak were calculated using the methods recommended in Chapter 6, Volume I of the Flood Studies Report (NERC, 1975).

Storm streamflow values were estimated as 'effective' rainfall from the two representative areas:-

$$
\begin{aligned}
\mathrm{Q}=\mathrm{a}_{1}[\mathrm{R}- & \left.\mathrm{SMD}_{1}\right]+\mathrm{a}_{2}\left[\mathrm{SMD}_{2}\right] \\
\text { where } \mathrm{Q} & \text { storm runoff }(\mathrm{mm}), \\
\mathbf{R} & \text { storm rainfall }(\mathrm{mm}), \\
= & \text { fractions of catchment having flat } \\
& \text { and steeply sloping areas (see } \\
& \text { above) } \\
\mathrm{a}_{1}, \mathrm{a}_{2} \quad & \\
\mathrm{SMD}_{1}, \mathrm{SMD}_{2}= & \text { antecedent soil moisture deficits } \\
& \text { (mm) measured by the mire and } \\
& \text { slope capacitance probes. }
\end{aligned}
$$

Inherent in this approach is the assumption that an area will only contribute to storm streamflow if and when the antecedent soil moisture deficit has been satisfied i.e. if 
$[\mathrm{R}-\mathrm{SMD}]$ is $-\mathrm{ve}$, then no storm runoff will be generated from that area.

\section{Results}

In order to determine the range of soil moisture that could be expected, the neutron probe data collected at monthly intervals between 1968 and 1974 were examined. Figure 1 shows the minimum, maximum and mean soil moisture profiles derived from the neutron probe data at the two sites. These profiles show clearly the differences in soil moisture between the two sites. For site 33, the 'slope' site, most of the variation occurs close to the ground surface whilst for site 35 , the 'mire' site, most of the variation occurs between 70 and $90 \mathrm{~cm}$ below ground level, at the peat/clay interface. For the top $50 \mathrm{~cm}$ of soil, the depth monitored in this study, the variation in soil moisture is $123.5 \mathrm{~mm}$ for the slope site and $73.0 \mathrm{~mm}$ for the mire site.

The frequencies recorded by the capacitance probes were converted to moisture content using simple regressions. The derivation of these regressions involved taking measurements with a capacitance probe and then, immediately, extracting a soil core at the same position for subsequent gravimetric determination. This was done at 5 and $10 \mathrm{~cm}$ depths at twelve sites on two separate occasions at Plynlimon. The sites chosen reflect the range of near surface soil moisture in the Wye catchment. Unfortunately, on neither occasion were the ground conditions as dry as were experienced for the slope station. For this reason, the calibration data from Plynlimon were supplemented by data from other locations for 'similar' organic soils.

A graph of gravimetric moisture volume fraction against capacitance probe frequency is given in Figure 2. An inverse relationship is obtained, as suggested by Dean, (1994). A number of single relationships were attempted unsuccessfully to simulate the calibration data. It was decided to use two formulations:

For moisture volume fraction $(\mathrm{MVF})>0.225$

$$
\mathrm{MVF}=\frac{1.5911}{(C P)^{2}}-1.121 \quad R^{2}=0.86
$$

For moisture volume fraction $(\mathrm{MVF})<0.225$

$$
\mathrm{MVF}=\frac{0.7643}{(C P)}-0.463 \quad R^{2}=0.71
$$

where $\mathrm{CP}$ is the capacitance probe frequency.

Problems were occasionally encountered with some of the capacitance probes. These were as a result of leakage during wet conditions and mainly affected the $50 \mathrm{~cm}$ depth probes, particularly in the mire area. As temporal variations at this depth were small, compared with those closer to the surface, it was decided to confine the analysis to data from the probes at 5,10 and $15 \mathrm{~cm}$ depths. Figure 3 shows monthly rainfall and the minimum, maximum and mean moisture volume fractions from both sites. Values for the mire site, where data exist, do not vary a great deal sea-
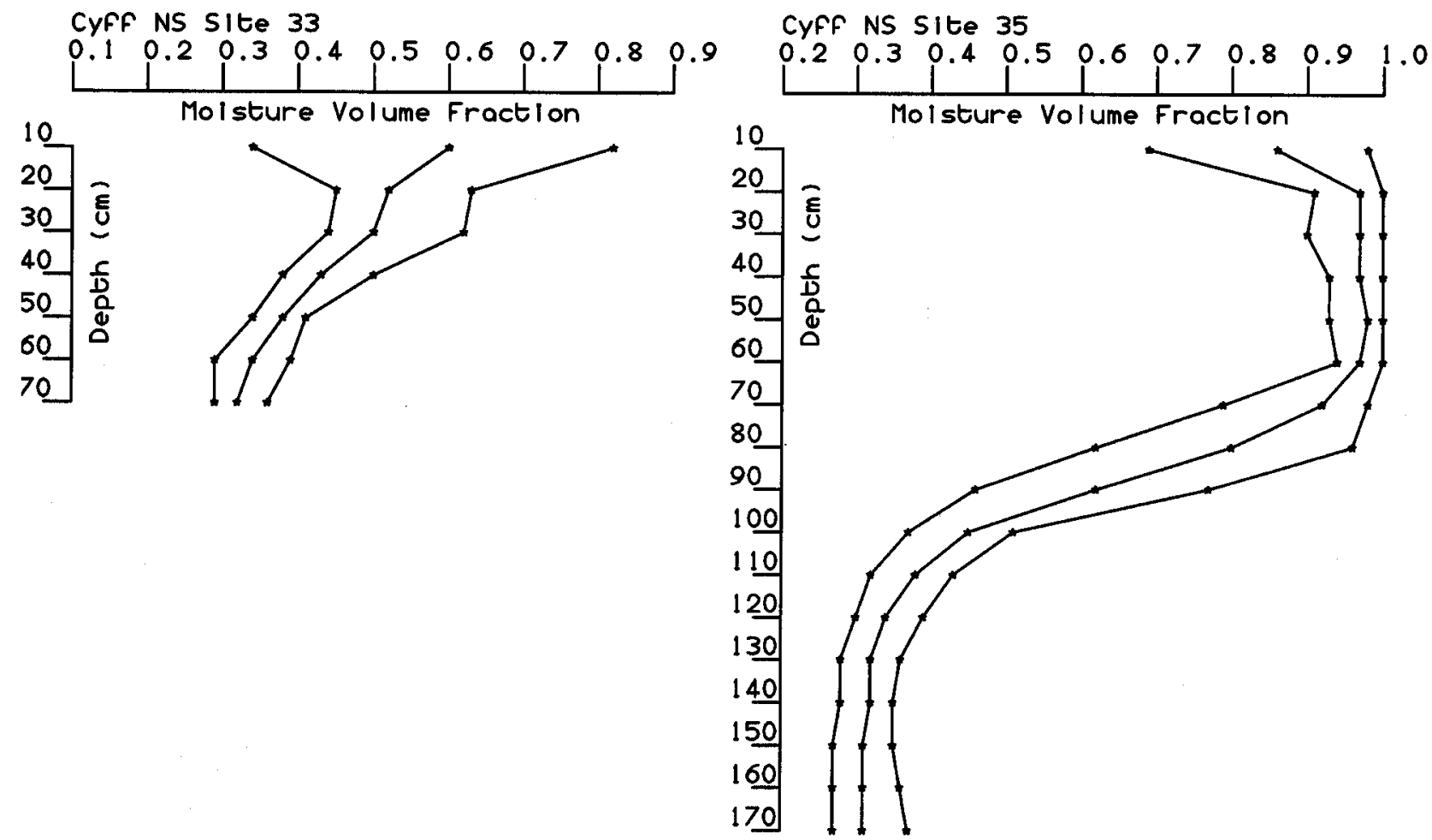

Figure 1 Minimum and maximum moisture volume fractions for the two sites as determined by neutron probe for the period $1968-1974$. 


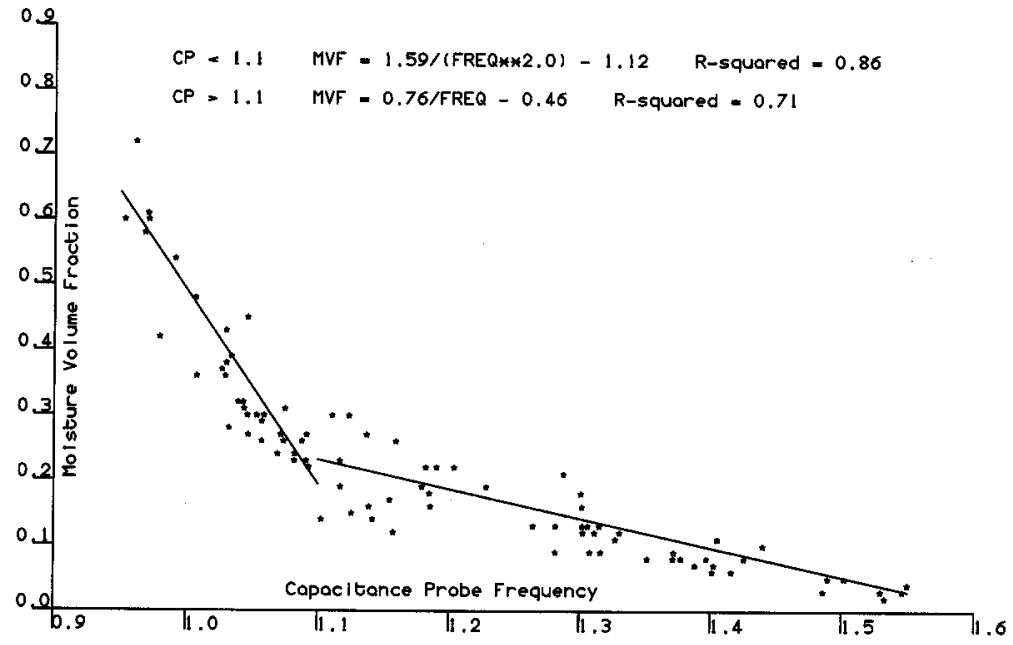

Figure 2 Capacitance probe calibrations
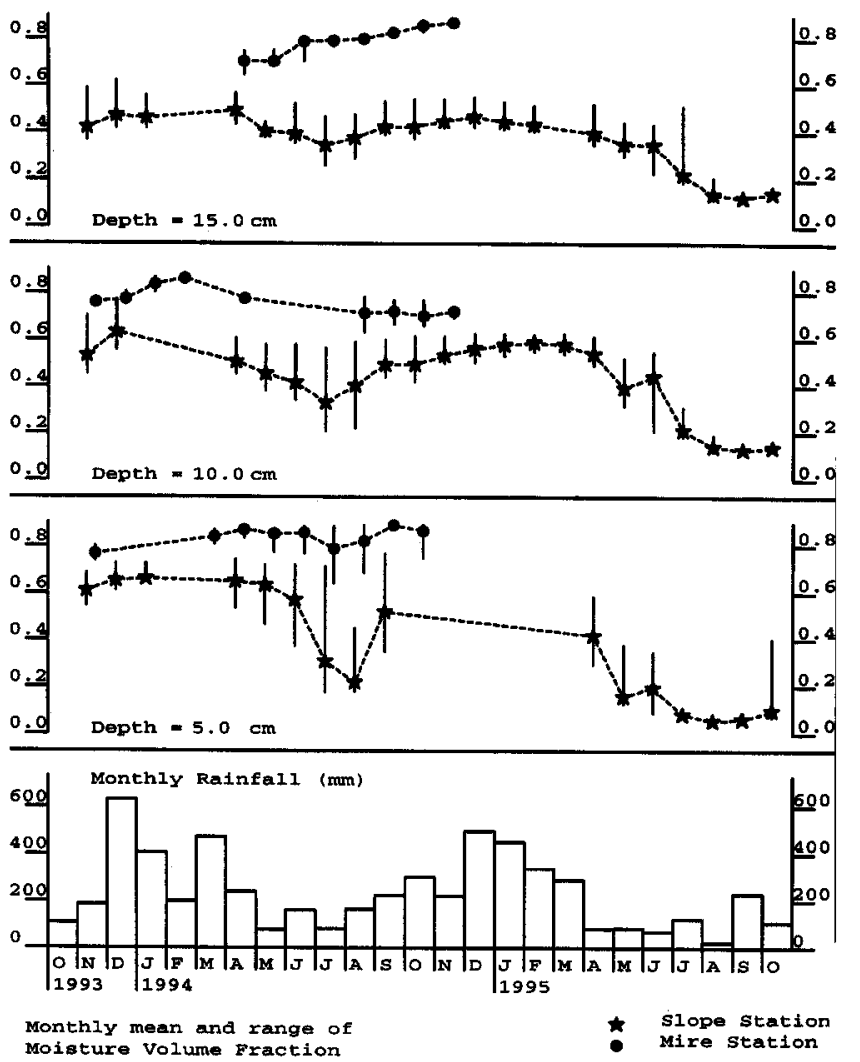

Figure 3 Monthly rainfall and moisture volume fractions at the two sites.

sonally or demonstrate a significant range for individual months. Also, the frequencies recorded in the mire area, when averaged over monthly periods, were usually outside of the range of the calibration data, though a number of individual values were within the range. For these reasons and increasing occurrences of data loss, the mire site was abandoned after twelve months. The data from the probes on the slope vary significantly for individual months, particularly in the summer, and show large seasonal variations with appreciable soil moisture deficits being generated during the summer months.

Thirteen suitable rainfall events were identified; of these the last three occurred during 1995 after the mire site had been abandoned. These three storms are used for illustration purposes only, and the data are not used for subsequent analysis. Details of all of the storms are given in Table 1, together with the response of the streamflow hydrographs of the Cyff and the Gwy. Storm rainfall totals vary between 13.0 and $60.5 \mathrm{~mm}$, with intensities in the range 0.7 to $4.7 \mathrm{~mm} /$ hour. The storms are spread evenly over the winter and summer periods. Storm streamflow totals, peak flows, and lag times for the two subcatchments are similar, with percentage runoff (NERC, 1975) varying between 5 and $90 \%$. Table 2 shows field capacity values and antecedent and peak soil moisture in the top $20 \mathrm{~cm}$ of soil for both the slope and mire areas. They were obtained by integrating moisture volume fractions from the probes at 5,10 and $15 \mathrm{~cm}$ depth assuming that each probe has a sphere of influence of radius $2.5 \mathrm{~cm}$ (Dean et al., 1987). The field capacity values are given by mean values recorded on days during the winter months 1993/4 following at least two days with no rain. Figure 4 shows hourly rainfall, hourly soil moisture deficit for the slope site and $15 \mathrm{~mm}$ flow in the Cyff for three contrasting storms. The data clearly demonstrate the effects of rainfall following differing antecedent conditions, with increases, almost to field capacity, during wetter periods. Very little response is observed during drier periods.

The data in Table 2 confirm that soil moisture changes are much smaller in the mire area than in the slope during storm events. Antecedent soil moisture in the mire area 
Table 1 Details of the storm events

\begin{tabular}{|c|c|c|c|c|c|c|c|}
\hline$\overline{\text { Date }}$ & $\begin{array}{l}\text { Rainfall } \\
(\mathrm{mm})\end{array}$ & $\begin{array}{l}\text { Duration } \\
\text { (hours) }\end{array}$ & Runoff & $\begin{array}{l}\text { Percentage } \\
(\mathrm{mm} / 15 \mathrm{~min})\end{array}$ & Initial Flow & $\begin{array}{l}\text { Peak Flow } \\
(\mathrm{mm} / 15 \mathrm{~min})\end{array}$ & $\begin{array}{l}\text { Lag Time } \\
\text { (hours) }\end{array}$ \\
\hline \multirow[t]{2}{*}{9.11 .93} & 33.5 & 13.0 & Cyff & $54 \%$ & 0.0078 & 0.4839 & 4.0 \\
\hline & & & Gwy & $62 \%$ & 0.0102 & 0.5408 & 3.75 \\
\hline 24.3 .94 & 60.5 & 13.0 & $\begin{array}{l}\text { Cyff } \\
\text { Gwy }\end{array}$ & $90 \%$ & 0.0736 & 1.7211 & 1.25 \\
\hline 31.3 .94 & 40.5 & 26.0 & $\begin{array}{l}\text { Cyff } \\
\text { Gwy }\end{array}$ & $74 \%$ & 0.0475 & 0.6680 & 1.0 \\
\hline \multirow[t]{2}{*}{5.5 .94} & 18.0 & 15.0 & Cyff & $43 \%$ & 0.0129 & 0.2364 & 5.25 \\
\hline & & & Gwy & $43 \%$ & 0.0180 & 0.1957 & 5.25 \\
\hline \multirow[t]{2}{*}{3.6 .94} & 30.0 & 24.0 & Cyff & $26 \%$ & 0.0086 & 0.3416 & 5.0 \\
\hline & & & Gwy & $32 \%$ & 0.0122 & 0.3298 & 5.0 \\
\hline \multirow[t]{2}{*}{ 21.6.94 } & 55.0 & 16.0 & Cyff & $58 \%$ & 0.0083 & 0.9056 & 3.75 \\
\hline & & & Gwy & $64 \%$ & 0.0126 & 1.0188 & 4.75 \\
\hline \multirow[t]{2}{*}{1.8 .94} & 16.0 & 12.0 & Cyff & $6 \%$ & 0.0052 & 0.0373 & 1.25 \\
\hline & & & Gwy & $5 \%$ & 0.0063 & 0.0336 & 2.25 \\
\hline \multirow[t]{2}{*}{16.8 .94} & 26.0 & 11.0 & Cyff & $12 \%$ & 0.0055 & 0.0557 & 4.25 \\
\hline & & & Gwy & $9 \%$ & 0.0067 & 0.0471 & 4.25 \\
\hline \multirow[t]{2}{*}{14.9 .94} & 36.0 & 19.0 & Cyff & $36 \%$ & 0.0585 & 0.3379 & 2.75 \\
\hline & & & Gwy & $24 \%$ & 0.0635 & 0.3502 & 2.5 \\
\hline \multirow[t]{2}{*}{1.10 .94} & 40.5 & 19.0 & Cyff & $56 \%$ & 0.0278 & 0.4161 & 4.25 \\
\hline & & & Gwy & $47 \%$ & 0.0319 & 0.3573 & 4.5 \\
\hline \multirow[t]{2}{*}{3.6 .95} & 13.0 & 25.0 & Cyff & $40 \%$ & 0.0125 & 0.1500 & 6.5 \\
\hline & & & Gwy & $35 \%$ & 0.0143 & 0.1063 & 6.25 \\
\hline \multirow[t]{2}{*}{14.7 .95} & 18.0 & 22.0 & Cyff & $14 \%$ & 0.0136 & 0.0413 & 9.0 \\
\hline & & & Gwy & $5 \%$ & 0.0052 & 0.0140 & 8.75 \\
\hline \multirow[t]{2}{*}{17.7 .95} & 54.7 & 14.0 & Cyff & $40 \%$ & 0.0079 & 0.8042 & 7.0 \\
\hline & & & Gwy & $43 \%$ & 0.0115 & 0.7688 & 6.75 \\
\hline
\end{tabular}

Table 2 Field capacities and antecedent and peak soil moisture contents $(\mathrm{mm})$ for the slope and mire areas

\begin{tabular}{lllll}
\hline & \multicolumn{2}{c}{ Slope Area } & \multicolumn{2}{c}{ Mire Area } \\
Field & \multicolumn{2}{c}{114.0} & \multicolumn{2}{c}{140.4} \\
Capacity & $\begin{array}{c}\text { Antecedent } \\
\text { Conditions }\end{array}$ & $\begin{array}{l}\text { Peak } \\
\text { Values }\end{array}$ & $\begin{array}{l}\text { Antecedent } \\
\text { Conditions }\end{array}$ & $\begin{array}{l}\text { Peak } \\
\text { Values }\end{array}$ \\
& & & & \\
Date & & & & \\
\hline 9.11 .93 & 89.2 & 109.8 & 141.2 & 141.4 \\
24.3 .94 & 94.1 & 109.4 & 136.2 & 136.2 \\
31.3 .94 & 95.3 & 111.4 & 136.4 & 136.7 \\
5.5 .94 & 91.5 & 104.0 & 133.8 & 136.8 \\
3.6 .94 & 79.8 & 97.6 & 140.5 & 143.7 \\
21.6 .94 & 66.7 & 107.5 & 143.6 & 147.6 \\
1.8 .94 & 39.3 & 55.6 & 133.6 & 146.2 \\
16.8 .94 & 44.0 & 62.0 & 125.9 & 139.4 \\
14.9 .94 & 83.3 & 104.4 & 143.5 & 143.7 \\
1.10 .94 & 88.3 & 109.8 & 144.5 & 144.5 \\
3.6 .95 & 53.7 & 64.4 & & \\
14.7 .95 & 24.4 & 26.0 & & \\
17.7 .95 & 26.4 & 30.7 & & \\
\hline
\end{tabular}

was normally above or close to field capacity, and deficits were only observed during August 1994. Even then, these were never greater than the storm rainfall totals shown in Table 1, and it is likely that these mire areas contributed to storm streamflow throughout 1994. In contrast, significant soil moisture deficits were observed on the slope in 1994. In some cases, notably during August 1994, these deficits were so high that they could not be satisfied by storm rainfall, and these areas ceased to contribute to storm streamflow.

Table 3 shows the results of regressing percentage runoff, peak flow, and lag time against soil moisture deficit in the slope area and antecedent flow for the Cyff and the Gwy. For the Cyff, some measure of agreement was found between the hydrograph characteristics and antecedent soil moisture, with correlation coefficients being similar to those obtained for antecedent flow, often used as an indicator of catchment wetness. For the Gwy, poor agreements were obtained for all regressions.

Effective rainfall using the formulation described in equation (1) was calculated for all the storms where soil moisture data from both sites were available. This was 

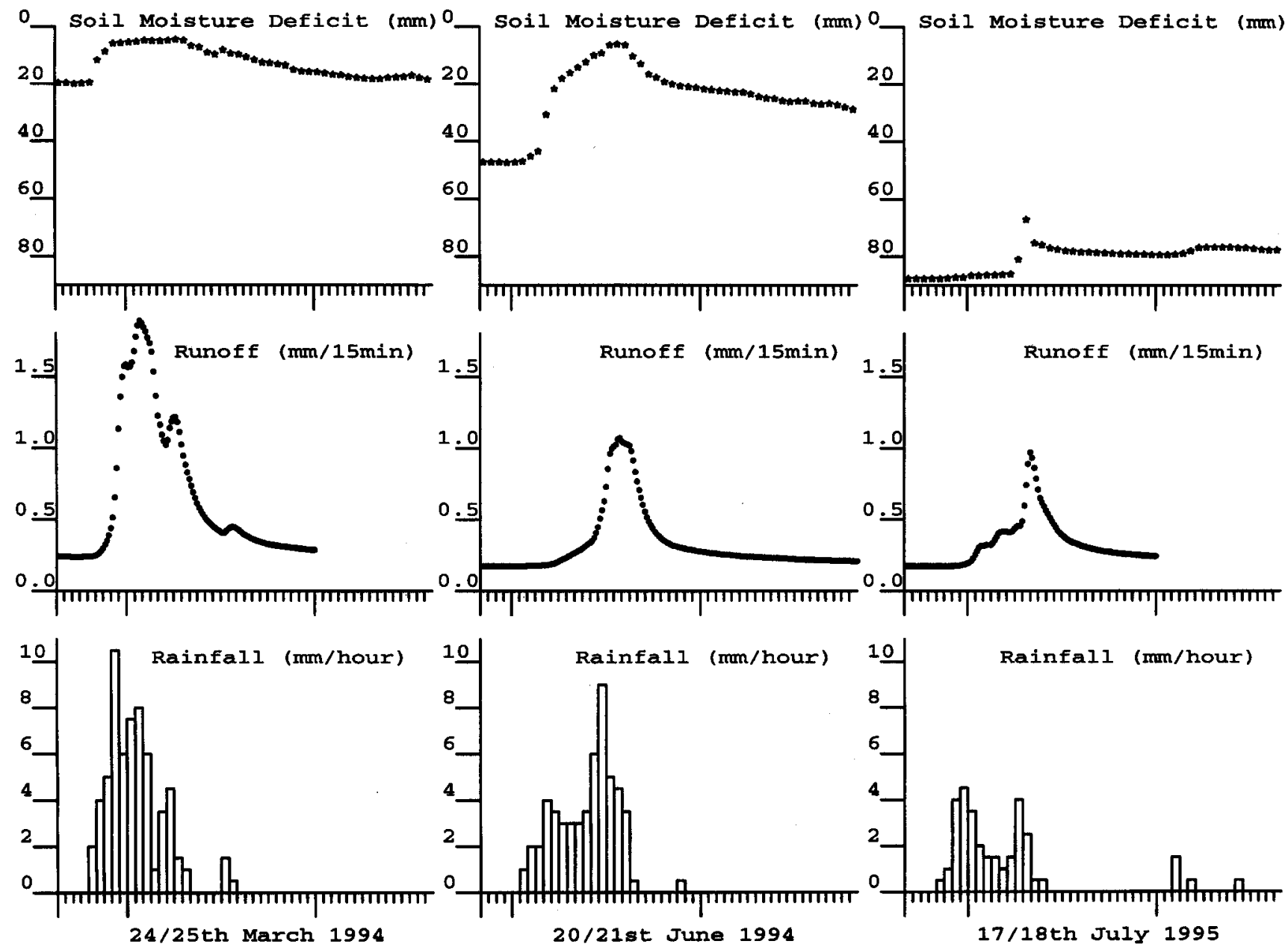

Figure 4 Rainfall, soil moisture deficit on the slope, and flow in the Cyff for three storms during contrasting periods.

Table 3 Regressions of percentage runoff, peak flow and lag time against soil moisture deficit on the slope and antecedent flow for the Cyff and the Gwy.

\begin{tabular}{lrllll}
\hline Cyff Sub-Catchment & & & Slope & Intercept & $\mathrm{R}^{2}$ \\
\hline \multirow{2}{*}{ (i) Percentage runoff } & vs. & SMD & -0.648 & 60.0 & 0.49 \\
& & antecedent flow & 697.1 & 26.7 & 0.42 \\
(ii) Peak flow & vs. & SMD & -0.007 & 0.670 & 0.16 \\
& & antecedent flow & 12.5 & 0.199 & 0.37 \\
(iii) Lag time & vs. & SMD & 0.051 & 2.86 & 0.32 \\
& & antecedent flow & -56.2 & 5.50 & 0.29
\end{tabular}

Gwy Sub-Catchment

\begin{tabular}{lrlccc} 
(i) Percentage runoff & vs. & SMD & -0.469 & 48.7 & 0.33 \\
& & antecedent flow & 99.4 & 31.8 & 0.01 \\
(ii) Peak flow & vs. & SMD & -0.002 & 0.42 & 0.04 \\
& & antecedent flow & 1.634 & 0.313 & 0.01 \\
(iii) Lag time & vs. & SMD & 0.035 & 3.79 & 0.23 \\
& & antecedent flow & -46.5 & 5.72 & 0.18 \\
\hline
\end{tabular}




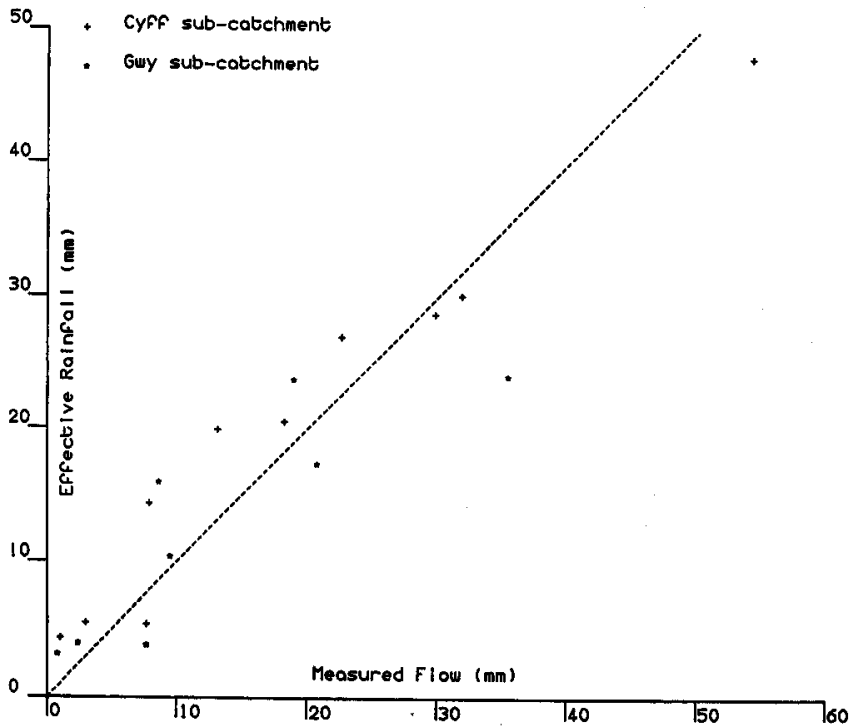

Figure 5 Measured storm streamflom and effective rainfall for the Cyff and the Gmy.

done for both the Cyff and the Gwy using the appropriate percentage areas. Measured storm streamflows and effective rainfall are tabulated in Table 4 and plotted against each other in Figure 5. Regressions of measured flow against effective rainfall give correlation coefficients of 0.95 and 0.75 for, respectively, the Cyff and the Gwy. However, when the values are inspected against a 1:1 line (Fig. 5), it can be seen that effective rainfall generally underestimates flow during smaller rain storms in dry conditions, with overestimates during larger storms.

Table 4 Measured storm streamflow ( $\mathrm{mm}$ ) and effective rainfall for the Cyff and the Gmy

\begin{tabular}{rrrrr}
\hline & \multicolumn{2}{c}{ Measured Storm } & \multicolumn{2}{c}{ Effective } \\
Runoff & \multicolumn{2}{c}{ Rainfall } \\
\multicolumn{1}{l}{ Date } & Cyff & Gwy & \multicolumn{1}{c}{ Cyff } & Gwy \\
\hline 9.11 .93 & 18.2 & 20.7 & 20.5 & 17.3 \\
24.3 .94 & 54.2 & & 48.0 & \\
31.3 .94 & 29.8 & & 28.7 & \\
5.5 .94 & 7.7 & 7.7 & 5.4 & 3.9 \\
3.6 .94 & 7.9 & 9.5 & 14.3 & 10.4 \\
21.6 .94 & 31.8 & 35.4 & 30.1 & 24.0 \\
1.8 .94 & 1.0 & 0.8 & 4.4 & 3.2 \\
16.8 .94 & 3.0 & 2.4 & 5.5 & 4.0 \\
14.9 .94 & 13.1 & 8.6 & 19.9 & 15.9 \\
1.10 .94 & 22.6 & 18.9 & 27.0 & 23.7 \\
& & & & \\
\hline
\end{tabular}

\section{Discussion}

An 'ideal' hill slope can be classified into nine slope elements (Dalrymple et al., 1968). These include all the pos- sible type of slopes that occur in nature. Individual elements are dependent on their position on the slope, the steepness and curvature. In reality, most slopes are complex with small scale variations and missing elements superimposed on to the ideal shape. This is certainly the case at Plynlimon, though Knapp (1970) identified five major slope elements, ignoring the stream bank and bed. These elements, with generalized descriptions taken from Knapp (1970) and Newson (1976) are:

\begin{tabular}{|c|c|c|c|c|}
\hline $\begin{array}{l}\text { Slope } \\
\text { element }\end{array}$ & Description & $\begin{array}{l}\text { Mean } \\
\text { slope }\end{array}$ & $\begin{array}{l}\text { Dominant } \\
\text { type }\end{array}$ & Drainage \\
\hline 2 & Upper convex & $<5^{\circ}$ & Caron & Very poor \\
\hline 3 & Middle convex slope & $>15^{\circ}$ & Manod & Well drained \\
\hline 5 & Upper concave slope & $10-15^{\circ}$ & Hiraethog & Less well drained \\
\hline 6 & Middle concave slope & $5-10^{\circ}$ & Hiraethog & Very poor \\
\hline 7 & Lower concave slope & $<5^{\circ}$ & Ynys & Very poor \\
\hline
\end{tabular}

In this study, it has been assumed that the slope site represents slope element 5, whilst that in the mire represents slope element 7.

Because of the heterogenous nature of the hillslopes at Plynlimon, downslope flow processes are very complex and, for modelling purposes, a number of generalisations has to be made (Bell, 1970). During dry conditions, hilltop areas (slope element 2) drain slowly through the peat onto the well drained hillslopes (slope elements 3 and 5); there the flow is diverted laterally downslope along an impeding layer until it reaches the partially or permanently saturated middle or lower concave slopes (slope elements 6 and 7). This water flows laterally through the upper few centimetres of the peat bog, before draining slowly into the stream channel. Baseflows within the Plynlimon streams are therefore sustained by the hilltop areas, where the water table falls as the dry conditions persist, and the valley bottoms or 'contributing' areas, which contract as the dry conditions persist (Dunne and Black, 1970).

During storm conditions, rain falling on the hilltop areas causes a rise in the water table. This increases the hydraulic gradient and results in greater subsurface flows to the steep slope areas. In some circumstances, hillslope areas can become saturated, resulting in saturation excess overland flow. This, together with rain falling on the hillslope areas, infiltrates vertically until it reaches an impeding layer, where it is again diverted laterally downslope. If the rainfall is of sufficient intensity and duration, the water table in these slope areas will rise and, in exceptional circumstances for Plynlimon, results in infiltration excess overland flow on to the middle and lower concave slopes. Alternatively, the increased drainage water leaving the hilltop areas can be intercepted by natural pipes which transport water rapidly to the saturated areas via seepage zones (Gilman and Newson, 1980).

In general, the input rate of water to the saturated valley bottom areas during storm events will be greater than 
the output to the stream. As a result, the saturated area will expand upslope, hydraulic gradients will become larger, and the rate of flow from the saturated area to the stream will increase. A detailed description of hillslope flow processes is given in Kirkby, (1988).

Given this simplified description of streamflow generation within the Wye catchment, the two instrumented sites seem to be well placed to monitor rainfall events, and the data are suitable for characterising streamflow hydrographs. The probes in the mire area monitor the contraction of the 'contributing' areas, whilst the probes on the slope indicate how much soil moisture deficit has to be satisfied before rainfall falling on the slope contributes to storm streamflow. Unfortunately, the loss of the mire site precluded data collection during July 1995 when soil moisture deficits may well have been significant. However, there is evidence from August 1994 that these areas do dry out occasionally. It would be useful if future work with capacitance probes could contribute to this aspect of streamflow generation, possibly in conjunction with other techniques (Chapter 3 in Gilman, 1994). The probes on the slope, on the other hand, demonstrated the different seasonal responses to rainfall inputs though, again, it is unfortunate that problems with the deeper probe limited the use of the data. Continuing instrument development will, hopefully, ensure an improved data return.

It is recognised that the approach in this study, particularly in the calculation of 'effective' rainfall, is a gross oversimplification, and it is surprising, and perhaps fortuitous that the agreement with storm streamflow totals is so good. Many assumptions have been made and there are a number of potential sources of error.

In the first place, the calculation of water content using the capacitance probe, in common with all non-destructive methods, is not a direct method, and requires a calibration based on the gravimetric water content of soil cores. This latter technique is subject to a number of uncertainties (Dean, 1994), though the possible error can be reduced by the use of a number of calibration points (Fig.2) or by using changes in soil moisture or relative values, as in soil moisture deficits.

Probably the greatest potential source of error is in the use of only two monitoring sites and their representivity. Although a great deal of analysis of the data from the neutron probe access tube network was done prior to installation, it is possible that alternative sites may well have contributed more information than those selected. In particular, it would have been desirable to monitor a hilltop and a partial contributing area midway between the monitored sites. The failure of remotely sensed images and a topographic index to provide a spatial representation of near surface soil moisture is disappointing but not altogether surprising. Small-scale variations in topography, soils, and vegetation, which occur at Plynlimon mean that spatial representation based on relatively coarse grid scales
( $28.5 \mathrm{~m}$ and $50 \mathrm{~m}$, respectively, for the Landsat images and topographic index) are unlikely to succeed (Gurnell and Gregory, 1986). In addition the analysis of the Landsat images was based on vegetation inference, and not on any direct measure of soil moisture. It is possible that algorithms being developed to analyse microwave images (Chapter 7 in Engman and Gurney, 1991) may be used for this purpose in the future.

The data from the recording capacitance probes have proved useful in characterising storm hydrographs. They have the advantage over conventional soil moisture measuring techniques of providing data from close to the soil surface, where the largest changes are likely to occur, and of providing continuous records prior to, and during the course of a storm. Similar instrumentation has been used elsewhere and has been found to be particularly useful in lowland catchments where spatial variations in soil moisture are less than those experienced at Plynlimon (Robinson and Stam, 1996).

\section{Conclusions}

Near surface soil moisture was recorded continuously using capacitance probes in two contrasting sites within the Wye catchment. It was found that:-

(i) In a mire area, very little temporal variation occurred, with small deficits being generated during prolonged dry spells. In contrast, large deficits were experienced on a steeply sloping hillslope.

(ii) Antecedent soil moisture on the slope area was well correlated with percentage runoff, but only weakly correlated with peak flow and lag time.

(iii) Effective rainfall, calculated using storm rainfall and the soil moisture deficits at the two monitored sites were in good agreement with measured storm streamflow.

\section{References}

Bell, J.P. and McCulloch, J.S.G., 1966. Soil moisture estimation by the neutron scattering method in Britain. 7. Hydrol., 4, 254-263.

Bell, J.P., 1970. The soil hydrology of the Plynlimon catchments. Institute of Hydrology Soil Moisture Section. Report no. 25.

Dalrymple, J.B., Blong, R.J. and Conacher, A.J., 1968. A hypothetical nine unit land surface model. Z. Geomorph., 12(1), 60-76.

Dean, T.J., Bell, J.P. and Baty, A.J.B., 1987. Soil moisture measurement by an improved capacitance technique. Part 1: Sensor design and performance. 7. Hydrol., 93, 67-78.

Dean, T.J., 1994. The IH capacitance probe for measurement of soil water content. Inst. Hydrol. Rep. no. 125.

Dunne, Thomas and Richard D. Black, 1970. Partial area contributions to storm runoff in a small New England Watershed. Wat. Resour. Res. 6(5), 1296-1311.

Engman, E.T. and Gurney, R.J., 1991. Remote Sensing in Hydrology, Chapman and Hall, London. 
Gilman, K. and Newson, M.D., 1980. Soil pipes and pipe flow: $a$ hydrological study in upland Wales. British Geomorphical Research Group Monograph no.1. Geobooks, Norwich.

Gilman, K., 1994. Hydrology and petland conservation. Wiley, Chichester, UK.

Gurnell, A.M. and Gregory, K.J., 1986. Water table level and contributing area: the generation of runoff in a heathland catchment. Conjunctive pater use. Int. Assoc. Hydrol. Sci. Publ., 156, 87-95.

Hasnip, N.J. (1993). A catchment based study of the spatial and temporal distribution of near surface soil moisture. Batchelor of Science Dissertation, Department of Geography, Coventry University, 79pp + Appendices.

Hudson, J.A., 1988. The contribution of soil moisture storage to the water balances of upland forested and grassland catchments. Hydrol Sci. 7., 33, 289-309.

Kirkby, M., 1988. Hillslope runoff processes and models. $\mathcal{f}$. Hydrol., 100, 315-339.
Knapp, B.J., 1970. Patterns of mater movement on a steep upland hillside, Plynlimon, Central Wales. Ph.D Thesis, University of Reading, pp. 213.

Newson, M.D., 1976. The physiography, deposits and vegetation of the Plynlimon catchments. Inst. Hydrol. Rep. no. 30, pp. 59.

NERC, 1975. Flood Studies Report. Natural Environment Research Council, London. 5 volumes.

Quinn, P., Beven, K., Morris, D. and Moore, R., 1989. The use of digital terrain data in modelling the response of hill slopes and headwaters. British Hydrological Society Symposium. University of Sheffield, $4-6$ September, 1989.

Robinson, M. and Dean, T.J., 1993. Measurements of near surface soil water content using a capacitance probe. $H y d r o l$. Process. 7. 7, 77-86.

Robinson, M. and Stam, M.H., 1996. A study of soil moisture controls on streamflow behaviour: results from the Ock basin, UK. Act Geologica Hispanica, 28 (2-3), 75-84. 